\title{
New host records for fish nematodes from Iran
}

\author{
J. Pazooki ${ }^{1 \star}$, F. Nazari Chamak ${ }^{1}$ and M. Masoumian ${ }^{2}$ \\ ${ }^{1}$ Faculty of Biological Sciences, Shahid Beheshti University, G. C. Tehran, Iran. \\ ${ }^{2}$ Department of Fish Diseases, Iranian Fisheries Research Organization, Tehran, Iran.
}

Accepted 16 January, 2012

\begin{abstract}
This study investigated the infections of nematodes in fish. A total of 244 fish specimens were examined in four stations (Halil, Shur, Konarooieh and Jafar Abad) of Kerman province southeastern Iran from June 2009 to June 2010. The fish under investigation were: Capoeta damascina (109 specimens), Cyprinion watsoni (79 specimens), Schistura sargadensis (34 specimens) and Channa gachua (22 specimens). The detected parasites were Rhabdochona macrostoma, Rhabdochona denudata, Contracaecum micropapillatum and Hepaticola petruschewkii. Of these $C$. damascina, $C$. watsoni, S. sargadensis and $C$. gachua were introduced as new hosts for these nematodes. The parasites $\boldsymbol{R}$. macrostoma and C. micropapillatum were the first to be recorded for these nematodes in Iran. The overall prevalence and the mean intensity of infections were 69.67 and $11.17 \%$, respectively. Nematode parasites are frequent in freshwater fish of different regions in Iran and must be taken into consideration for aquaculture.
\end{abstract}

Key words: Parasites, Kerman Province, rhabdochonidae, anisakidae, capillaridae, cyprinidae, chanidae.

\section{INTRODUCTION}

Nematodes are frequently regarded as one of the most important and harmful worm parasites that affect fish. They can kill the host fish by serious mechanical harm from excessive movement that puts a strain on the host, killing the fish and having a detrimental effect on the fishing industry (Moravec, 1994, Woo 1995).

There are relatively few studies on nematode parasites that infect fish in Iran (Ebrahim-Zadeh and Nabavi, 1976; Ebrahim-Zadeh and Keylani, 1976; Pazooki, 1996; Pazooki and Masoumian, 2001; Pazooki et al., 2003, 2008). To improve aquaculture in South-eastern Iran for the prevention of the losses of fish stock, there are needs for more information available on the parasite fauna that affects wild fish which may be transferred to farms. In aquaculture systems, brood stock infected with a small number of nematodes may not even show signs of illness, but they often have reduced productivity rates; however, juvenile fish infected by small numbers of nematodes are more likely to show signs of illness and reduced growth rates (Yanong, 2002).

The aim of this study is to investigate the parasitic fauna of freshwater fish in water reservoirs of Kerman

\footnotetext{
${ }^{\star}$ Corresponding author. E-mail: pazooki2001@yahoo.com.
}

Province in Iran.

\section{MATERIALS AND METHODS}

Fish sampling was carried out between June 2009 and June 2010. A total of 244 fish specimens were collected from four stations including: Halil-Rud, Abshur, Konarooieh and Jafarabad Rivers that is located in Kerman Province. The fish was caught with an electro shoker, fixed and stored in $4 \%$ formalin and transferred to the aquatic research laboratory. The fish species were Capoeta damascina (109 specimens), Cyprinion watsoni (79 specimens), Schistura sargadensis (34 specimens) and Channa gachua (22 specimens). The external bodies, visceral cavities and digestive tracts were examined for any presence of nematode parasites. Dissection and examination of the fish specimens was carried out under a dissecting microscope as described by Heckman (1995) and Hoffman (1999). The collected nematodes were fixed in $4 \%$ formalin and cleared in glycerin for examination. Photograph was taken with the aid of a microscope that was equipped with micrometers and a Sony camera. Identification of the parasites was carried out using morphometric and morphology criteria as described by Moravec $(1994,1998)$ and Bykhovskaya, (1964).

\section{RESULTS}

From a total of 244 examined fish, 161 specimens were found to be infected with various nematodes. The observed 
nematode parasites were identified to species level. They were Rhabdochona denudata, Rhabdochona macrostoma, Hepaticola petruschewkii and Contracaecum micropapillatum. Table 1 listed the character of hosts that were examined and their parasites. To describe the occurrences of the various parasites in different fish, the following parameters were determined: prevalence of infections (percentage of infected individuals), and mean intensity of infection (mean number of parasites per infected host) (Table 2).

\section{Rhabdochona denudata}

\section{Description}

Medium sized nematodes with a smooth cuticle. Tail of both sexes had ends in a sharp cuticular spike (Dujardin, 1845).

Male: The length of the body was 2.76 to $6.47 \mathrm{~mm}$, the width was 0.081 to $0.183 \mathrm{~mm}$, muscular esophagus was 0.193 to $0.887 \mathrm{~mm}$, and the glandular esophagus measured 1.74 to $2.37 \mathrm{~mm}$. There were 10 to 12 pre anal papilla, 5 post anal papilla, large spicule length of 0.396 to $2.249 \mathrm{~mm}$, and a shaft that slightly exceeded half of its length. Its distal tip had a ventral tooth-like process formed by spicular cover, small spicule length of 0.075 to $0.114 \mathrm{~mm}$ with a reflected dorsal barb at the tip.

Female: The body of a gravid female had a length of 7.201 to $14.09 \mathrm{~mm}$, the maximum width was 0.112 to $0.204 \mathrm{~mm}$, muscular esophagus was 0.55 to $0.295 \mathrm{~mm}$, glandular esophagus was 2.172 to $3.15 \mathrm{~mm}$. The tail conical was 0.195 to $0.261 \mathrm{~mm}$ and the egg was oval containing larva; size of egg was 0.021-0.024 × 0.039$0.048 \mathrm{~mm}$ (Figure 1A, B, C, D). This nematode was found in fishes' intestines.

\section{Rhabdochona macrostoma}

\section{Description}

A relatively short body with a smooth cuticle. The tail of both sexes was conical with a sharp terminal cuticular spike (Moravec and Mikailov, 1970).

Male: The length of body was 4.53 to $6.25 \mathrm{~mm}$, width was 0.139 to $0.163 \mathrm{~mm}$, the muscular esophagus was 0.43 to $0.66 \mathrm{~mm}$, glandular esophagus 1.53 to $2.20 \mathrm{~mm}$. The pre anal and post anal papilla were 9 and 5, respectively.

Female: The body of gravid female was 5.28 to $6.44 \mathrm{~mm}$ long, with a maximum width of 0.204 to $0.285 \mathrm{~mm}$, muscular esophagus was 0.735 to $0.816 \mathrm{~mm}$ and glandular esophagus was 2.68 to 2.72 . The mature eggs were oval, with dimensions of 0.03 to $0.036 \times 0.018$ to $0.021 \mathrm{~mm}$ with larva inside, with a filament of fibrous structure (Figure 2A, B, C). Infected organ was the fishes' intestines.

\section{Hepaticola petruschewkii}

\section{Description}

The body was of filiform (cuticular bands were absent). The anterior part of the female body was half as long as its posterior. The vulva opened in the esophageal region (Shulman, 1948).

Female: The length of their body is 1.35 to $1.95 \mathrm{~mm}$, and the width is 0.44 to $0.81 \mathrm{~mm}$. The eggs have thick striated shell with two readily discarded plugs, and the length of the egg with the plugs was $0.04 \times 0.02 \mathrm{~mm}$ (Figure 3A, B, C). Adult worms infected the intestines and their eggs were found in the liver parenchyma.

\section{Contraceacum micropapillatum larvae}

\section{Description of the third stage, the larvae}

Length of the body was 2.92 to $3.78 \mathrm{~mm}$ with a maximum width of 0.13 to $0.32 \mathrm{~mm}$. Anlagen of lips and larval tooth were present. Length of the esophagus was 0.377 to $0.438 \mathrm{~mm}$. They had a small ventriculus, intestinal caecum length of 0.163 to $0.4 \mathrm{~mm}$, the length of tail 0.102 to $0.173 \mathrm{~mm}$ (Figure 4A, B). The intestine was the infected organ (Stossich, 1890).

\section{DISCUSSION}

Between agents that cause infection in fish of freshwater, brackish-water and marine environments throughout the world, nematodes are of particular importance because they cause mechanical and nutritional deficiencies in the host. Present knowledge of these parasites still remains incomplete, especially those pertaining to biology and ecology, but also taxonomy, phylogeny and zoogeography (Moravec, 2007).

This study has revealed that freshwater fish examined for parasitic infections from Kerman Province in Iran were infected with the following four nematode species: $R$. denudata, $R$. macrostoma, $H$. petruschewkii and $C$. micropapillatum and they belong to the Rhabdochonidae, Anisakidae and Capillaridae families. Three species of Rhabdochona have been reported from freshwater fish in Iran: $R$. denudata, Rhabdochona fortunatiwi (Pazooki and Masoumian, 2001), and Rhabdochona helichi (Eslami et al., 1972). The general morphology and measurements of Rhabdochona specimens that are found in this study 
Table 1. Fish length and weight with list of their parasites.

\begin{tabular}{|c|c|c|c|c|}
\hline Host & Number & Total length $(\mathrm{cm})$ & Weight $(g)$ & Parasites \\
\hline Capoeta damascina & 109 & $5.6-18.2$ & $2.2-81.9$ & $\begin{array}{l}\text { Rhabdochona denudata } \\
\text { Rhabdochona macrostoma } \\
\text { Hepaticola petruschwekii } \\
\text { Contracaecum micropapilatum }\end{array}$ \\
\hline Cyprinion watsoni & 79 & 4.1-16.3 & $1.9-55.2$ & $\begin{array}{l}\text { Rhabdochona denudata } \\
\text { Hepaticola petruschewkii }\end{array}$ \\
\hline Schistura sargadensis & 34 & $5.5-6.7$ & $0.7-2.9$ & Rhabdochona denudata \\
\hline Channa gachua & 22 & $6.9-16.1$ & $4-46.7$ & Rhbdochona denudata \\
\hline Total & 244 & -.-- & --- & --. \\
\hline
\end{tabular}

Table 2. The prevalence and mean intensity of infection.

\begin{tabular}{llccc}
\hline Hosts & Parasites & Infected fishes & Prevalence (\%) & Mean intensity \\
\hline \multirow{4}{*}{ Capoeta damascina } & Rhabdochona denudata & 80 & 73.39 & 9.45 \\
& Rhabdochona macrostoma & 3 & 2.75 & 2 \\
& Hepaticola petruschewkii & 4 & 3.66 & 4 \\
& Contracaecum micropapilatum & 5 & 4.58 & 1.6 \\
Cyprinion watsoni & Rhabdochona denudata & 70 & 88.60 & 15.82 \\
& Hepaticola petrushewkii & 4 & 5.06 & 1 \\
S. sargadensis & & & & 1 \\
Channa gachua & Rhabdochona denudata & 1 & 2.94 & 3 \\
Total & Rhabdochona denudata & 3 & 13.63 & 11.17 \\
\hline
\end{tabular}

corresponded to $R$. denudata and $R$. macrostoma. Plenty of infections with $R$. denudata were significant in each of the four specimens. This species is particular to the observations reported only from the intestines of the host fish.

In Iran, the first record of $R$. denudata was made by Pazooki and Masoumian (2001), it was reported from Leucisus cephalus in Tadjan and Gorgan-Rud Rivers in the Caspian Sea water basin. This parasite was also reported from the intestine of Cyprinion macrostomum, Barbus pectoralis, Barbus luteus, Cyprinus carpio, Silurus triostegus, Barbus grypus, Barbus Sharpeyi in Hoorshadegan (Mortezaei et al., 2007), C. macrostomum in Iraq (Moravec et al., 1991) and Leucius cephalus in Turkey (Aydogdu et al., 2001) and in Czechoslovakia (Moravec, 1994). All four fish that were examined in this study provided records of a new host for this parasite.

$R$. macrostoma deposited from intestine of $C$. damascina. This parasite was originally described by Moravec (1994) from the intestine of Varocorhinus capoeta in freshwater in Azerbaijan. This was the first record of an observation in Iran. C. damacsina therefore this was a new host for this nematode.

$H$. petruschewkii was reported in the liver of Capoeta capoeta gracilis, Alburnoides bipinctatus, from Tadjan and Babol-Rud Rivers, in the Caspian Sea water body (Hassan et al., 2008) in Ruff, Spin loach, Bleu perch, from the Danube River, Vyrtsyarv, Black and Baltic Lakes (Bychovskaya, 1964). In this study, this nematode was reported from $C$. damascina and $C$. watsoni, and both fish are the new hosts recorded for this parasite.

Third-stage larva of Contraceacum micropapillatum was reported from $C$. damasina intestine. This parasite was reported for the first time in this fish and in Iran. Both the host and the locality are new.

The highest prevalence of infection was registered in $C$. watsoni for $R$. denudata $(88.60 \%)$, with a mean intensity of 15.82. The lowest prevalence was found in $C$. damascina infected with $R$. macrostoma $(2.75 \%)$ (Table 2).

The results show that varieties of nematode were high in terms of territorial distribution, as well as in zoogeographical and ecological aspects. This demonstrates that distribution of these parasite species 

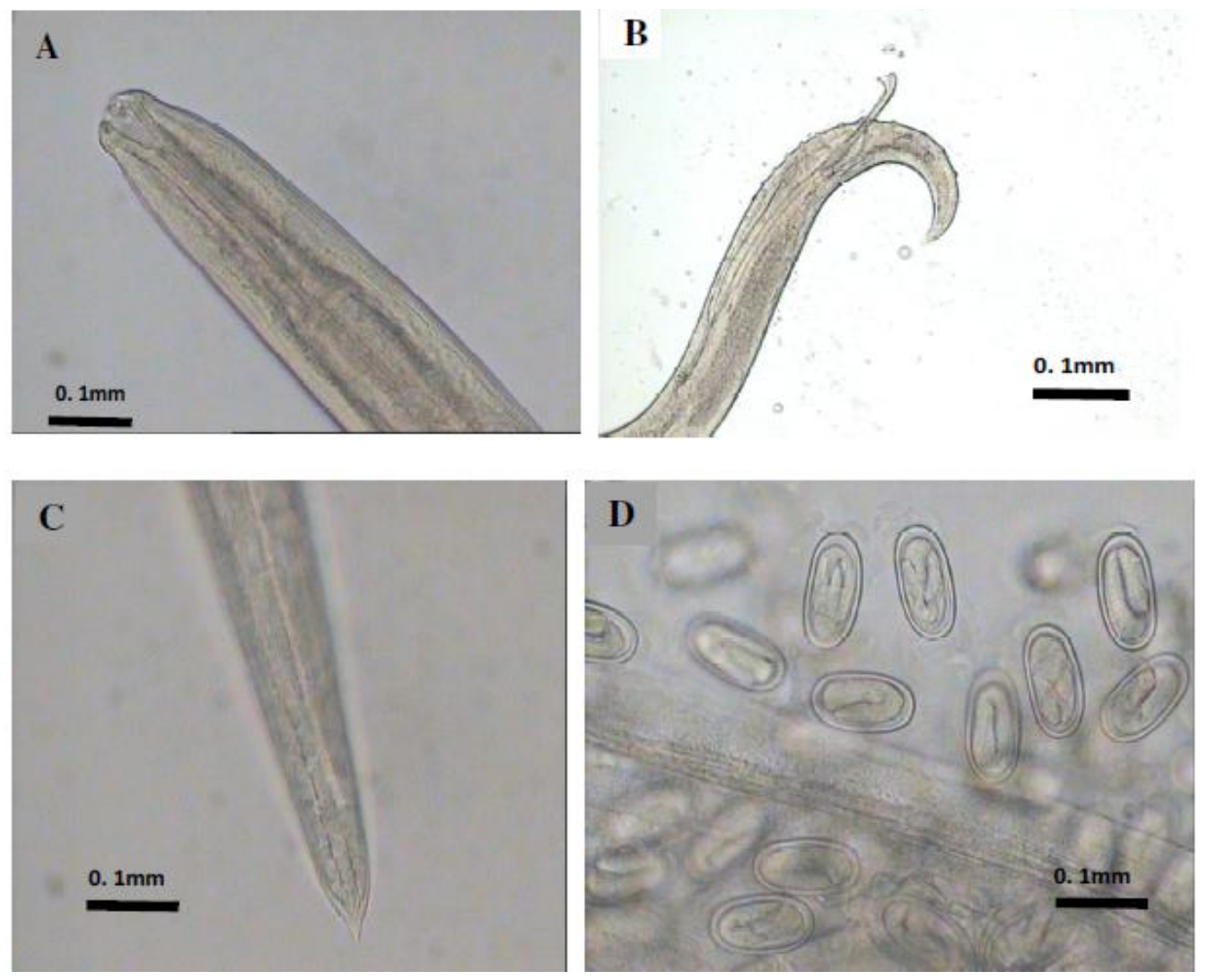

Figure 1. Rhabdochona denudata; (A) Anterior part of the body, (B) posterior part of male, (C) posterior part of female, (D) the eggs.
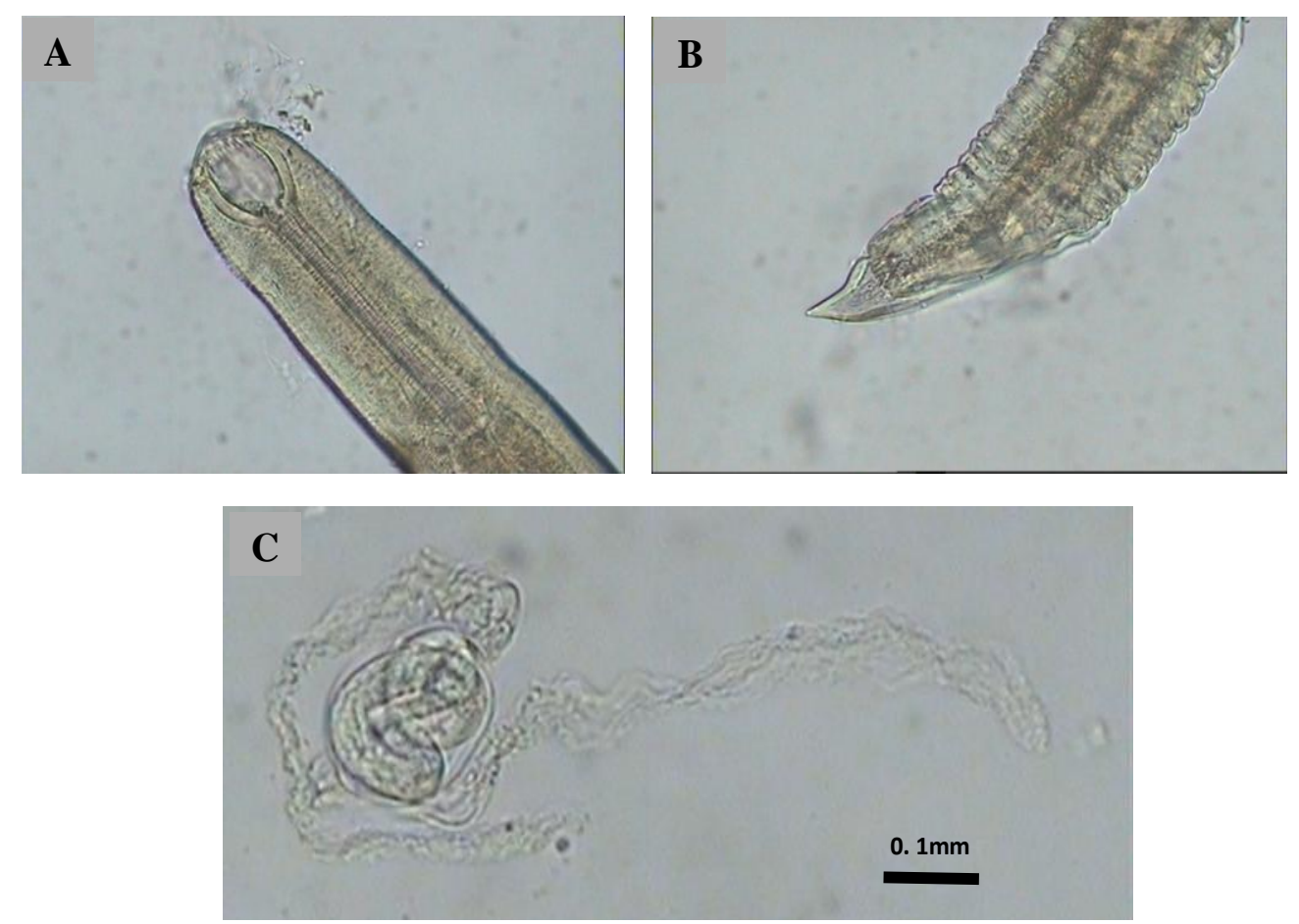

Figure 2. Rhabdochona macrostoma; (A) Anterior part of the body, (B) posterior part of the body, (C) the eggs. 

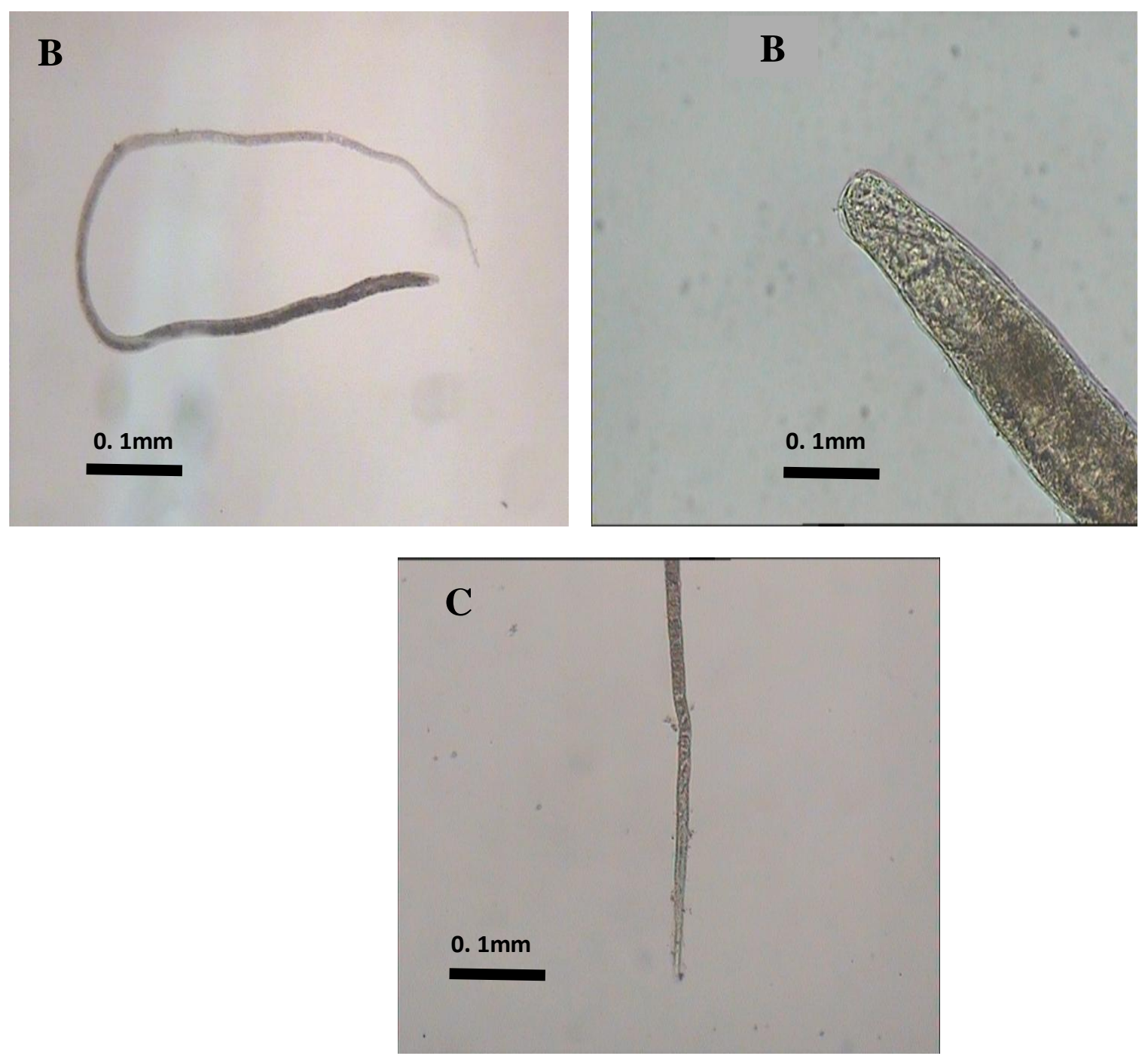

Figure 3. Hepaticola petruschewkii; (A) the whole body, (B) anterior part of the body, (C) posterior part of the body.
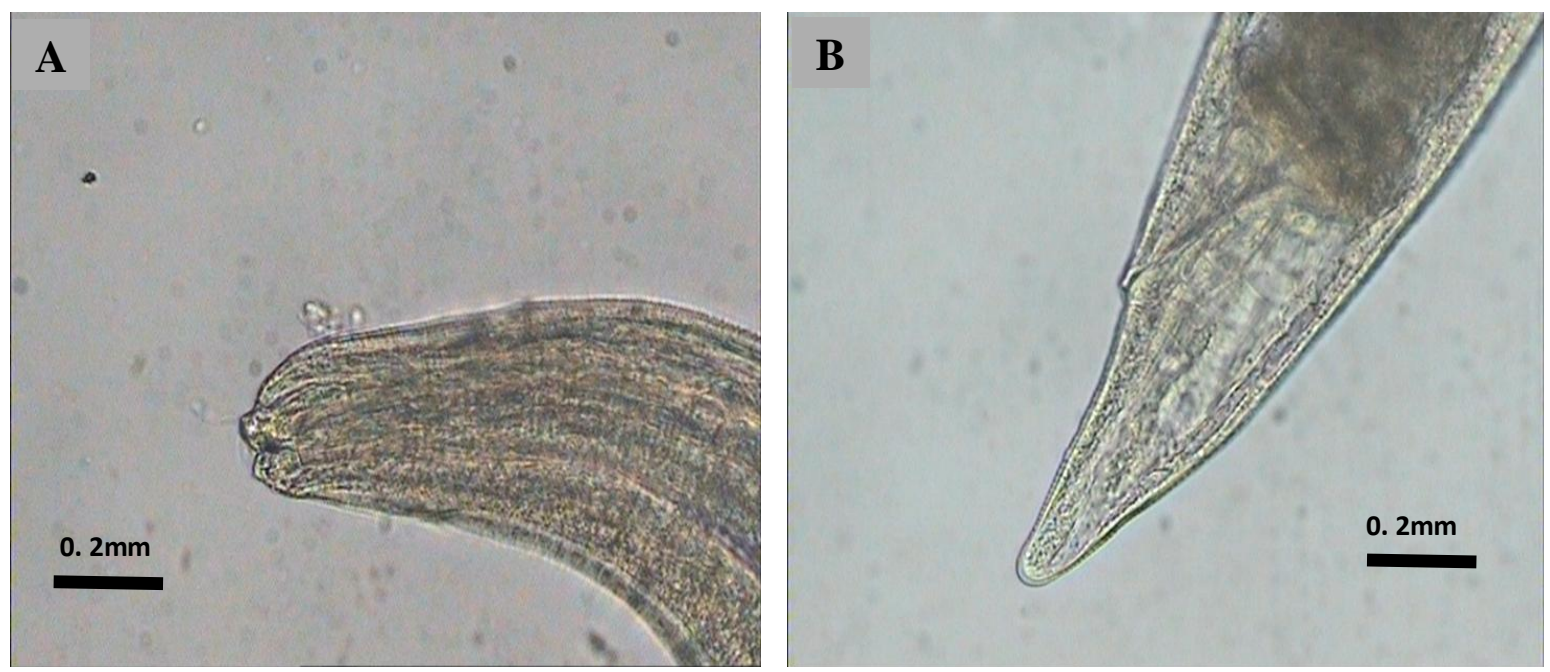

Figure 4. Contracaecum micropapilatum; (A) anterior part of the body, (B) posterior part of the body. 
can be dispersed, and consideration needs to be given to the fact that they may survive in different climates. With the exception of $H$. petruschewkii, the other nematodes were not necessarily associated with the disease.

\section{REFERENCES}

Aydogdu A, Altunel FN, Yildirimhan HS (2001). Occurrence of helminth in chub, Leuciscus cephalus, of the Doganci Dam, Turk. Bull. Eur. Assoc. Fish Pathol., 21(6): 246-251.

Bychovskaya BE (1964). Key to the parasites of freshwater fishes of USSR translation from Russian by palestin program for scientific translation. Jerusalem, p. 458.

Eslami AM, Anwar M, Khatibi SH (1972). Incidence and intensity of helminthosis in Pike (Esox esox) of Caspian Sea (North Iran). Rivista. It. Piscicult. Ittiop, 77: 11-14.

Hassan PQ, Qashem ZF, Rahimian H (2008). First record from introduce three metazoan parasites in Cyprinids fishes (Cyprinidae) in Tadjan and Babol-Rud Rivers. Tehran Univ. J., 30(3): 529-540.

Heckman RA (1995). Managing and Understanding Fish Health. Aqua Mag., p. 43-57.

Hoffman GL (1999). Parasites of North American Fresh Water Fishes. 2nd ed. Cornel Univ Press, p. 283.

Moravec F (1994). Parasitic Nematodes of freshwater fishes of Europe. Acad. Sci. Czech Repub., p. 473.

Moravec F (1998). Parasitic Nematodes of freshwater fishes of the Neotropical Region. Academy of Science of the Czech Repulic, Inst. Parasitol., p. 473.
Moravec F, Ali NM, Abdul - Eis ES (1991). Observation on two Rhabdochona species (Nematodae: Rhabdochonidae) from freshwater fishes in Iraq including description of $\mathrm{R}$. similis. Folla Parasitol., 38: 235-243.

Moravec F (2007). Nematode Parasites of fishes: Recent advances and problems of their research. Parassitologia, 49(3): 155-160

Mortezaei SRS, Pazooki J, Masoumia M (2007). Nematodes from freshwater fishes of Khouzestan Province. Pajouhesh and sazandegi. 77: 2-10.

Pazooki J (1996). A funestical survey and histopatological studies on freshwater fish nematodes in Iran and Hungary. Ph.D Thesis. Vet. Med. Res. Ins. Hung. Acta. Sci. Hungary., p. 98.

Pazooki J, Masoumian M (2001). Nematodes from freshwater fishes of Guilan And Mazandaran Provinces. Pajouhesh and Sazandegi, 51: 93-99.

Pazooki J, Masoumian M, Yahyazadeh M, Abbasi J (2008). Metazoan parasites from freshwater fishes of Northwest. J. Agric. Sci. Technol., 9: 25-33.

Woo PTK (1995). Fish Diseases and Disorders, volume 1, protozoan and metazoan infections, CAB international, U.K., p. 791.

Yanong RPE (2002). Nematode (Roundworm) infections in fish. First edition. CooperativeExtension Service, Inst. Food Agric. Sci. Univ. Florida, U.S.A., p. 16. 